\title{
Relativistic electron beams above thunderclouds
}

\author{
M. Füllekrug ${ }^{1}$, R. Roussel-Dupré ${ }^{2}$, E. M. D. Symbalisty ${ }^{3}$, J. J. Colman ${ }^{4}$, O. Chanrion ${ }^{5}$, S. Soula ${ }^{6}$, O. van der Velde ${ }^{7}$, \\ A. Odzimek ${ }^{8}$, A. J. Bennett ${ }^{9,}$, , V. P. Pasko ${ }^{10}$, and T. Neubert ${ }^{5}$ \\ ${ }^{1}$ University of Bath, Centre for Space and Atmospheric Research, Dept. of Electronic and Electrical Engineering, Bath, UK \\ ${ }^{2}$ SciTech Solutions, Melbourne, Florida, USA \\ ${ }^{3}$ Atmospheric, Earth and Environment Sciences Division, Los Alamos National Laboratory, Los Alamos, New Mexico, USA \\ ${ }^{4}$ Kirtland Airforce Base, USAF AFMC AFRL/RVBXP, New Mexico, USA \\ ${ }^{5}$ National Space Institute, Technical University of Denmark, Copenhagen, Denmark \\ ${ }^{6}$ Laboratoire d'Aérologie, Université de Toulouse, Toulouse, France \\ ${ }^{7}$ Department of Electrical Engineering, Universitat Politècnica de Catalunya, Terrassa, Spain \\ ${ }^{8}$ Institute of Geophysics, Deptartment of Atmospheric Physics, Polish Academy of Sciences, Warsaw, Poland \\ ${ }^{9}$ Passive Sensing, Met Office, Exeter, UK \\ ${ }^{10}$ Department of Electrical Engineering, Pennsylvania State University, Pennsylvania, USA \\ *also at: University of Bath, Centre for Space and Atmospheric Research, Department of Electronic and Electrical \\ Engineering, Bath, UK
}

Received: 25 April 2011 - Published in Atmos. Chem. Phys. Discuss.: 20 May 2011

Revised: 16 July 2011 - Accepted: 20 July 2011 - Published: 3 August 2011

\begin{abstract}
Non-luminous relativistic electron beams above thunderclouds have been detected by the radio signals of low frequency $\sim 40-400 \mathrm{kHz}$ which they radiate. The electron beams occur $\sim 2-9 \mathrm{~ms}$ after positive cloud-to-ground lightning discharges at heights between $\sim 22-72 \mathrm{~km}$ above thunderclouds. Intense positive lightning discharges can also cause sprites which occur either above or prior to the electron beam. One electron beam was detected without any luminous sprite which suggests that electron beams may also occur independently of sprites. Numerical simulations show that beams of electrons partially discharge the lightning electric field above thunderclouds and thereby gain a mean energy of $\sim 7 \mathrm{MeV}$ to transport a total charge of $\sim-10 \mathrm{mC}$ upwards. The impulsive current $\sim 3 \times 10^{-3} \mathrm{Am}^{-2}$ associated with relativistic electron beams above thunderclouds is directed downwards and needs to be considered as a novel element of the global atmospheric electric circuit.
\end{abstract}

\section{Introduction}

Sprites (Neubert et al., 2008; Füllekrug et al., 2006; Rakov and Uman, 2003; Sentman et al., 1995; Franz et al., 1990) and gigantic jets (Cummer et al., 2009; Su et al., 2003; Pasko et al., 2002) are luminous streamer (Luque and Ebert, 2009;

Correspondence to: M. Füllekrug (eesmf@bath.ac.uk)
Pasko et al., 1998) and leader (Riousset et al., 2010; Krehbiel et al., 2008; Pasko and George, 2002) discharges resulting from conventional electrical breakdown in the middle atmosphere. Sprites may also be associated with electron beams resulting from relativistic runaway breakdown within or above thunderclouds (Østgaard et al., 2008; Inan, 2005; Smith et al., 2005; Roussel-Dupré and Gurevich, 1996; Fishman et al., 1994). The newly-recognised runaway breakdown mechanism (Gurevich and Zybin, 2005; Gurevich et al., 1992) inside thunderclouds (Shao et al., 2010; Dwyer et al., 2009) can initiate at $\sim 1 / 10$ of the conventional breakdown electric field threshold (Marshall et al., 1995) and requires a population of energetic seed particles to initiate an electromagnetically radiating non-linear electron avalanche growth (Gurevich et al., 2003). The population of seed particles must be above the runaway threshold of $\sim 10 \mathrm{keV}$ or more, depending on the strength of the electric field, and could originate from $\sim 10^{15}-10^{16} \mathrm{eV}$ cosmic rays (Gurevich et al., 2009; Gurevich and Zybin, 2005) or thermal runaway in leader and/or streamer tips (Celestin and Pasko, 2011; Colman et al., 2010; Moss et al., 2006). The runaway avalanche can result in a population of electrons with energies as high as tens of MeV inside the thundercloud (Shao et al., 2010; Dwyer et al., 2009; Gurevich et al., 1992). Whether relativistic electron beams can also occur above thunderclouds is currently not known (Østgaard et al., 2008; Inan, 2005; Smith et al., 2005; Roussel-Dupré and Gurevich, 1996; Fishman et al., 1994) even though transient narrow beams of

Published by Copernicus Publications on behalf of the European Geosciences Union. 


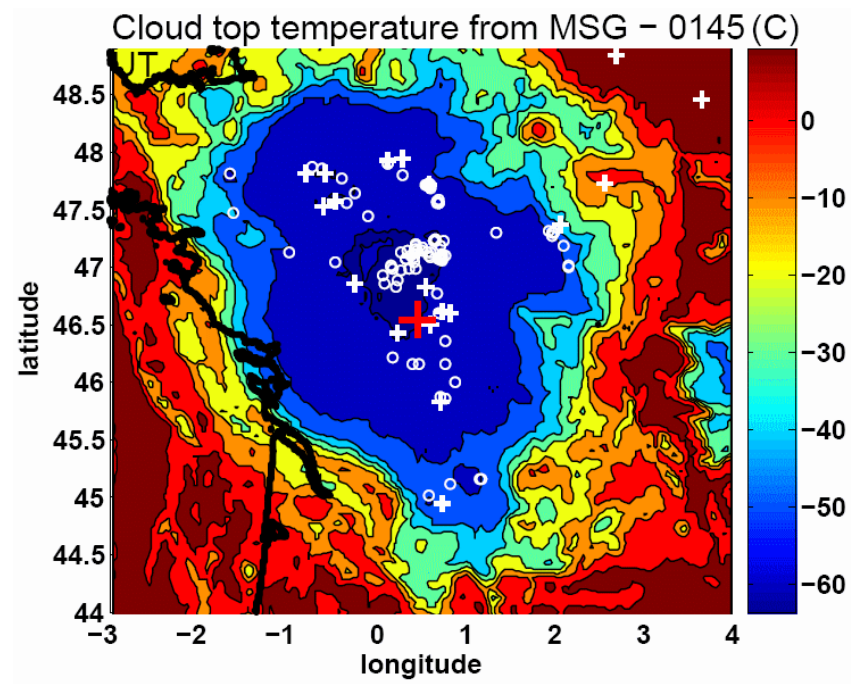

Fig. 1. A meso-scale convective system is located over France and reaches an area of $\sim 400 \times 400 \mathrm{~km}^{2}$ at $01: 45$ UTC on $31 \mathrm{Au}-$ gust 2008 as inferred from the cloud top infrared brightness temperature. Many negative lightning discharges (circles) cluster in the $\sim 12 \mathrm{~km}\left(T_{\min }=-64 \mathrm{C}^{\circ}\right)$ high convective core of the thunderstorm surrounded by some positive lightning discharges (crosses). One particular positive lightning discharge (red cross) at 01:52:59.524 UTC causes a sprite discharge above the thundercloud. The size of the red cross indicates the area covered by individual sprite elements.

relativistic electrons are now routinely observed in space (Briggs et al., 2011; Cohen et al., 2010; Carlson et al., 2009; Dwyer et al., 2008). Relativistic electron beams are occasionally associated with sprites as inferred from radio remote sensing with low frequency radio signals from $\sim 40-400 \mathrm{kHz}$ (Füllekrug et al., 2010). These radio signals are analyzed here in detail to determine the height of relativistic electron beams above thunderclouds and to determine the associated charge transfer through the middle atmosphere.

\section{The mesocale convective system, lightning discharges and sprites}

Thunderstorms and lightning activities in southern Europe have recently attracted special interest because numerous sprites are observed with video cameras above thunderclouds which regularly develop during the summer months from the beginning of May to mid-September (Soula et al., 2009; Neubert et al., 2008). For example, several thundercloud cells initiated over the Bay of Biscay and northern Spain in the late afternoon on 30 August 2008. The thunderstorms migrated northward through France and merged to an exceptional mesoscale convective system during the night until it decayed away in the late morning hours when reaching the English Channel which prevented an intrusion into Great Britain. The mesoscale convective system developed to a

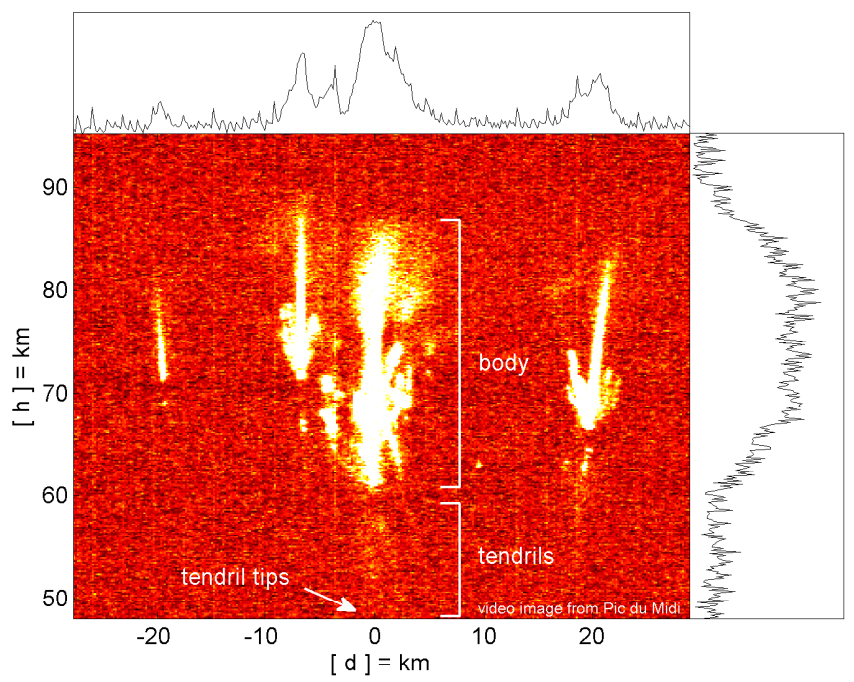

Fig. 2. The main body of the sprite extends upwards from $\sim 60-85 \mathrm{~km}$ height and the tendrils of the sprite extend downwards from $\sim 60-50 \mathrm{~km}$ as triangulated by use of two video cameras from Pic du Midi in the French Pyrénées $\left(42.9^{\circ} \mathrm{N}, 0.1^{\circ} \mathrm{E}\right)$ and Sant Vicenç de Castellet in North-Eastern Spain $\left(41.7^{\circ} \mathrm{N}, 1.9^{\circ} \mathrm{E}\right)$. The sprite body is surrounded by three columniform sprites at distances up to $\sim 20 \mathrm{~km}$. The panels on the top and right hand side indicate the relative luminosity of the sprite which is inferred from the intensity of the image pixels.

maximum area of $\sim 400 \times 400 \mathrm{~km}^{2}$ as inferred from the cloud top infrared brightness temperature recorded on board the Meteosat Second Generation (MSG) satellite at 01:45 UTC (Fig. 1). The convective core of the thunderstorm reached a height of $\sim 12 \mathrm{~km}$ with cloud top temperatures as low as $\sim-64 \mathrm{C}^{\circ}$. Many negative lightning discharges cluster in the convective core which is surrounded by some positive lightning discharges reported by the French lightning detection system Météorage at the time when Meteosat scanned the electrified thundercloud from 01:50 UTC to 02:00 UTC.

One particular positive lightning discharge at 01:52:59.524 UTC $\left(46.54^{\circ} \mathrm{N}, 0.48^{\circ} \mathrm{E}\right)$ with a peak current of $\sim 47.1 \mathrm{kA}$ reported by Météorage causes a sprite discharge above the thundercloud (Fig. 2) which is observed with a video camera located on the top of Pic du Midi in the French Pyrénées $\left(42.93^{\circ} \mathrm{N}, 0.14^{\circ} \mathrm{E}, 2877 \mathrm{~m}\right.$ elev.) and another video camera located in Sant Vicenç de Castellet in North-Eastern Spain $\left(41.67^{\circ} \mathrm{N}, 1.86^{\circ} \mathrm{E}, 193 \mathrm{~m}\right.$ elev.). The sprite discharge consists of the main body of the sprite surrounded by three columniform sprites at distances up to $\sim 20 \mathrm{~km}$. The main body of the sprite extends upwards from $\sim 60 \mathrm{~km}$ to $\sim 85 \mathrm{~km}$ height as triangulated by use of the two video cameras. The sprite tendrils extend downwards from $\sim 60 \mathrm{~km}$ to $\sim 50 \mathrm{~km}$ below the main body of the sprite.

The sprite luminosity curve is delayed by $\sim 3-6 \mathrm{~ms}$ with respect to the causative positive lightning discharge (Fig. 3) as evidenced by high speed $(20 \mathrm{kHz})$ recordings with a 

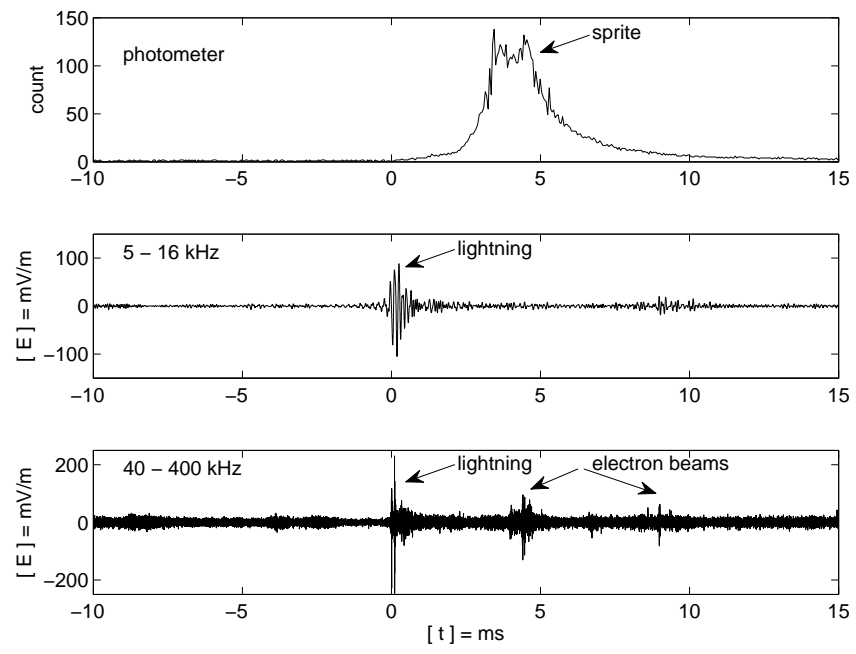

Fig. 3. The sprite luminosity occurs $\sim 3-6 \mathrm{~ms}$ after the causative positive lightning discharge at $0 \mathrm{~ms}$ (upper panel) as observed from Pic du Midi with a high-speed photometer. The lightning discharge emits a burst of electromagnetic radiation in the frequency range from $\sim 5-16 \mathrm{kHz}$ (middle panel) which is recorded with a wideband digital radio receiver in South-West England $\left(51.3^{\circ} \mathrm{N}\right.$, $\left.2.3^{\circ} \mathrm{W}\right)$. Two consecutive bursts of electromagnetic radiation in the frequency range $\sim 40-400 \mathrm{kHz}$ occur at $\sim 4.4 \mathrm{~ms}$ and $\sim 8.9 \mathrm{~ms}$ (bottom panel). These bursts are thought to be caused by relativistic electron beams above the thundercloud.

photometer located at Pic du Midi and vertical electric field recordings with a wideband digital radio receiver (Füllekrug, 2010) located near Bath in South-West England of the United Kingdom $\left(51.35^{\circ} \mathrm{N}, 2.29^{\circ} \mathrm{W}\right)$. The sprite causing positive cloud-to-ground lightning discharge causes a strong burst of electromagnetic radiation which spans the entire frequency range of the radio receiver. A large fraction of this electromagnetic energy is deposited in the narrow frequency range from $\sim 5-16 \mathrm{kHz}$ which is typical for cloud-to-ground and intra-cloud lightning discharges (Said et al., 2010) as a result of the large scale quasi-continuous flow of current. Two much smaller consecutive bursts of electromagnetic radiation occur $\sim 4.4 \mathrm{~ms}$ and $\sim 8.9 \mathrm{~ms}$ after the lightning discharge. They do not deposit a large fraction of their electromagnetic energy in the frequency range from $\sim 5-16 \mathrm{kHz}$ which is untypical for conventional lightning discharges. The first radiation burst coincides with the sprite luminosity at $\sim 4.4 \mathrm{~ms}$. The second radiation burst shortly follows the sprite luminosity after $\sim 4.5 \mathrm{~ms}$. Both radiation bursts are thought to be caused by electron beams above the thundercloud resulting from relativistic runaway breakdown (Füllekrug et al., 2010).

\section{Relativistic electron beams}

Seven similar untypical broadband bursts of electromagnetic radiation following sprite-producing lightning discharges have been collected during sprite observations in the years 2008 and 2009 (Table 1). In these two years, a total of $\sim 140$ sprite observations have been examined such that the occurrence rate of the electromagnetic radiation bursts is $\sim 5 \%$. These bursts all occured $\sim 2-9 \mathrm{~ms}$ after sprite-producing positive cloud-to-ground lightning discharges. The average spectrum of the seven bursts is relatively flat at frequencies $<40 \mathrm{kHz}$ when compared to the average spectrum of their parent lightning discharges (Fig. 4, left). This is consistent with simulations of virgin air high frequency breakdown. The spectral amplitudes of the broadband electromagnetic radiation bursts are as small as $\sim 100 \mu \mathrm{Vm}^{-1} \mathrm{~Hz}^{-1 / 2}$ in the frequency range from $\sim 40-400 \mathrm{kHz}$, but still $\sim 1-2$ orders of magnitude above an average background spectrum which is recorded $10 \mathrm{~ms}$ prior to the causative lightning discharges for reference (Fig. 4, left). This background spectrum exceeds the ultimate sensitivity limit of the wideband digital radio receiver $\sim 1-2 \mu \mathrm{Vm}^{-1} \mathrm{~Hz}^{-1 / 2}$ by $\sim 1$ order of magnitude (Fig. 4, right). Superimposed on the sensitivity limit of the receiver are the omni-present low-frequency, or longwave, radio transmitters in this frequency range, e.g., the United Kingdom radio clock at $60 \mathrm{kHz}$ (the former Rugby MSF signal, now transmitted from Anthorn), France Inter at $162 \mathrm{kHz}$, Europe 1 at $183 \mathrm{kHz}$, and BBC radio 4 at $198 \mathrm{kHz}$. These radio transmitters have a typical narrow bandwidth of $\sim 10-12 \mathrm{kHz}$ and they exhibit similar spectral amplitudes when compared to the observed broadband $(\sim 40-400 \mathrm{kHz})$ radiation bursts from electron beams.

Numerical simulations of relativistic electron beams above thunderclouds predict theoretically broadband bursts of electromagnetic radiation with a flat spectrum following spriteproducing lightning discharges (Füllekrug et al., 2010) in agreement with our experimental observations. These model calculations solve kinetic particle equations on the microscopic scale and Maxwell's equations on the macroscopic scale simultaneously. The causative lightning continuing current drains charge from the thundercloud which exposes the area above the thundercloud to a quasi-static electric field. When this electric field exceeds the runaway breakdown threshold and the continuous flux of high-energy secondary cosmic ray electrons (Daniel and Stephens, 1974, Fig. 2) supplies sufficient energetic seed electrons (RousselDupré et al., 1998, p. 920, eq. in right col.), an electron avalanche above the thundercloud is initiated which quickly develops into an upward propagating relativistic electron beam. The beamed electrons partially discharge the lightning electric field and thereby gain a mean energy of $\sim 7 \mathrm{MeV}$ with a spread of $\sim 6 \mathrm{MeV}$ while carrying a total charge of $\sim-10 \mathrm{mC}$ upward as inferred from the comparison between the measured and simulated electron beam spectrum (Fig. 4, left and right). Impulsive changes of this downward 
Table 1. Observations of several electron beams associated with sprites. The date, time, and location of the causative lightning discharges are reported by the French lightning detection system Météorage. The distances between the lightning discharges and the wideband digital radio receiver in South-West England vary between $\sim 490-1060 \mathrm{~km}$. The electromagnetic radiation bursts from the lightning discharge and the consecutive electron beam exhibit time delays from $\sim 2-9 \mathrm{~ms}$. The time delays between the direct wave and the sky wave from the electron beam can only be determined for distances up to $\sim 500 \mathrm{~km}$ as a result of the larger signal to noise ratio of the electromagnetic recordings. The observed time delays from $\sim 25-92 \mu$ s indicate that all the electron beams are located at heights between $\sim 16-72 \mathrm{~km}$, well above the top of the thundercloud at $\sim 12 \mathrm{~km}$ (Fig. 1). The last listed event at 01:29 UTC on 31 August was not associated with any sprite and it indicates that relativistic electron beams may also occur independently of sprites. The full range of techniques described in the methodology section was used during observations from 00:00-04:00 UTC on 31 August 2008.

\begin{tabular}{|c|c|c|c|c|c|c|c|}
\hline date & time/UTC & location & $\begin{array}{r}\text { lightning } \\
\text { peak current/kA }\end{array}$ & $\begin{array}{r}\text { lightning/receiver } \\
\text { distance } / \mathrm{km}\end{array}$ & $\begin{array}{r}\text { lightning/beam } \\
\text { delay/ms }\end{array}$ & $\begin{array}{r}\text { direct/sky wave } \\
\text { delay/ } / \mu \mathrm{s}\end{array}$ & $\begin{array}{r}\text { height } \\
\mathrm{km}\end{array}$ \\
\hline 31.08 .2008 & $01: 52: 59.524482$ & $0.4767^{\circ} \mathrm{E}, 46.5408^{\circ} \mathrm{N}$ & 47,1 & 571 & $4.4 / 8.9$ & $59 / 25$ & $41 / 72$ \\
\hline 31.08 .2008 & $02: 18: 26.265226$ & $0.5489^{\circ} \mathrm{E}, 46.8654^{\circ} \mathrm{N}$ & 73.1 & 540 & 8.0 & 92 & 16 \\
\hline 31.08 .2008 & $02: 42: 20.621219$ & $0.3618^{\circ} \mathrm{E}, 47.3155^{\circ} \mathrm{N}$ & 60.4 & 489 & 2.5 & 75 & 22 \\
\hline 24.08.2009 & $21: 04: 24.032714$ & $2.0992^{\circ} \mathrm{E}, 43.6166^{\circ} \mathrm{N}$ & 42.2 & 920 & 2.0 & - & - \\
\hline 24.08.2009 & $21: 18: 11.336514$ & $1.8931^{\circ} \mathrm{E}, 43.8959^{\circ} \mathrm{N}$ & 37.9 & 886 & 7.0 & - & - \\
\hline 02.09 .2009 & 02:09:56.601840 & $3.5730^{\circ} \mathrm{E}, 42.8089^{\circ} \mathrm{N}$ & 52.0 & 1048 & 5.5 & - & - \\
\hline 02.09.2009 & $02: 56: 15.533414$ & $4.3115^{\circ} \mathrm{E}, 42.9315^{\circ} \mathrm{N}$ & 11.6 & 1060 & 2.0 & - & - \\
\hline 31.08 .2008 & 01:29:09.786166 & $0.3979^{\circ} \mathrm{E}, 46.6625^{\circ} \mathrm{N}$ & 63.1 & 557 & 5.5 & 60 & 43 \\
\hline
\end{tabular}

(a)

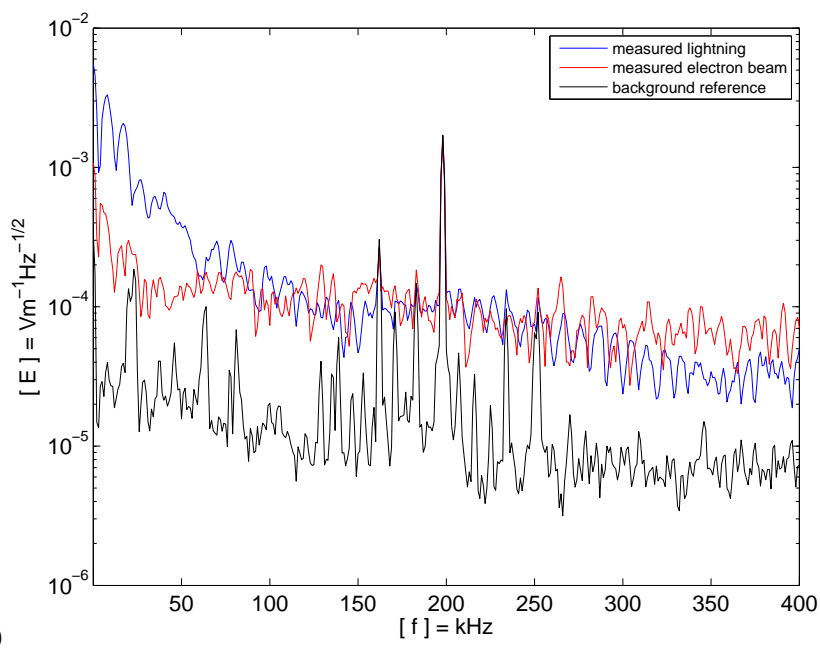

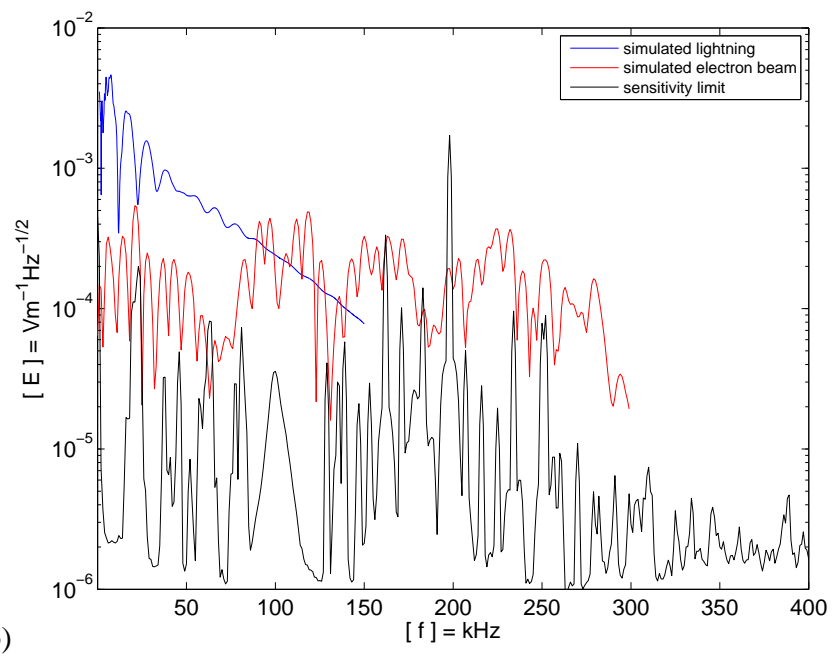

Fig. 4. The average spectra of radiation from electron beams (red lines) and their causative lightning discharges (blue lines) on the left compare well with the theoretical simulations on the right. (a): The average spectrum of radiation produced by the seven measured electron beams (Table 1) is relatively flat at frequencies $<40 \mathrm{kHz}$ (red line) when compared with the average spectrum of their causative lightning discharges (blue line). The lightning and electron beam spectra are $\sim 1-2$ orders of magnitude larger than the average background spectrum (black line) which is recorded $10 \mathrm{~ms}$ prior to the causative lightning discharges for reference. (b): The radiation from the simulated electron beam is relatively flat at frequencies $<40 \mathrm{kHz}$ (red line) when compared with the simulated spectrum of the causative lightning discharge (blue line). The simulated spectra are $\sim 2-3$ orders of magnitude larger than the sensitivity limit of the wideband digital radio receiver $\sim 1-2 \mu \mathrm{Vm}^{-1} \mathrm{~Hz}^{-1 / 2}$ which is inferred from time intervals without any bursts of electromagnetic radiation (black line). Superimposed on this ultimate reference spectrum are the omni-present low frequency, or long wave, radio transmitters, the strongest of which is here the BBC Radio 4 transmitter at $198 \mathrm{kHz}$, which exhibits spectral amplitudes comparable to the measured and simulated electron beam.

current from the electron beam $\sim 3 \times 10^{-3} \mathrm{Am}^{-2}$, i.e., its displacement current, results in the observed bursts of electromagnetic radiation a few $\mathrm{ms}$ after the causative lightning discharge.

The initial lightning discharge and the subsequent electron beam launch electromagnetic waves which can propagate on several paths from the source location to the radio receiver. These propagation paths can be inferred from a detailed analysis of the observed electromagnetic radiation bursts. The burst of electromagnetic radiation from the lightning discharge is composed of two consecutive pulses which are delayed by $\sim 102 \mu$ s (Fig. 5, upper panel). The first pulse results 

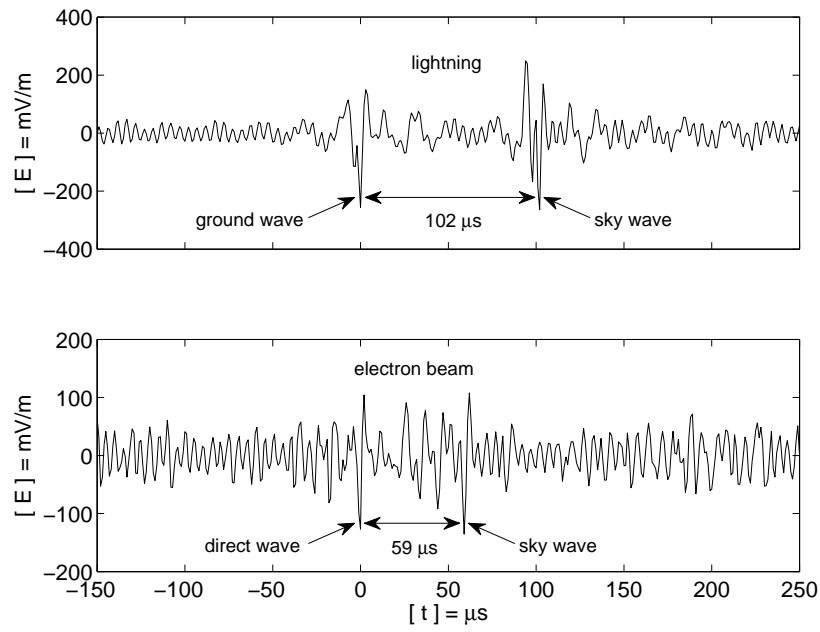

Fig. 5. The burst of electromagnetic radiation from the lightning discharge is composed of two consecutive pulses which are delayed by $\sim 102 \mu$ s (upper panel). The first pulse results from the electromagnetic wave which propagates along the surface of the Earth to the receiver (ground wave). The second pulse results from the electromagnetic wave which is reflected from the ionosphere (sky wave). The burst of electromagnetic radiation from the electron beam is also composed of two consecutive pulses (lower panel). The short time delay of $\sim 59 \mu$ s indicates that the electron beam is located above the thundercloud where it emits an electromagnetic wave which propagates at an angle to the receiver (direct wave).

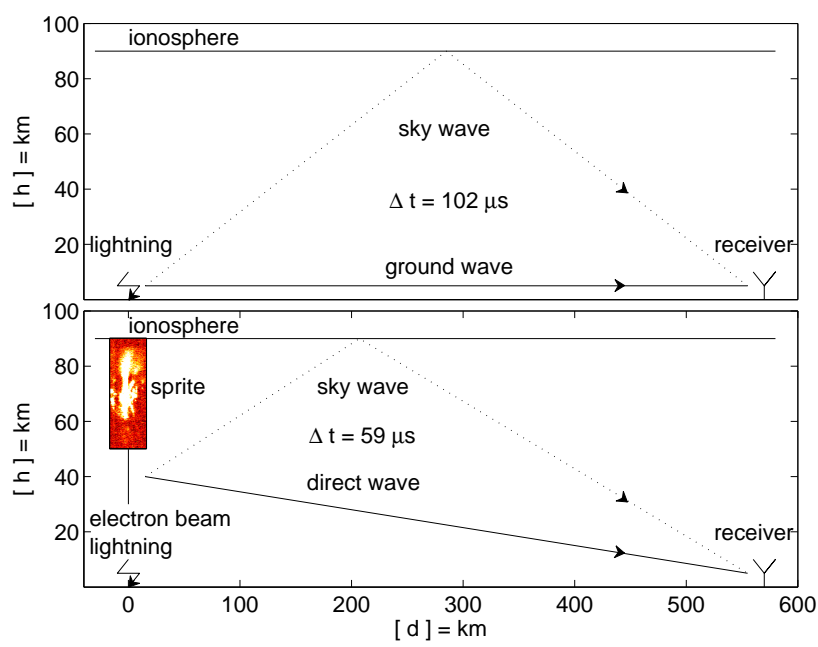

Fig. 6. The time delay of $\sim 102 \mu$ s between the ground wave and the sky wave from the lightning discharge indicates that the reflecting ionosphere is located at a height of $\sim 90 \mathrm{~km}$ (upper panel). The time delay of $\sim 59 \mu$ s between the direct wave and the sky wave from the electron beam indicates that the electron beam is located at a height of $\sim 41 \mathrm{~km}$ (lower panel). The electron beam does not emit enough photons at visible wavelengths to exceed the sensitivity limit of the charge coupled device chip of the video camera. It is concluded that electron beams above thunderclouds can coincide with sprites but that they independently discharge lightning electric fields above thunderclouds. from the electromagnetic wave which propagates from the lightning discharge to the receiver along the surface of the Earth and is denoted ground wave. The second pulse results from the electromagnetic wave which is reflected from the ionosphere and is denoted sky wave. The time delay between the ground and sky wave determines the ionospheric reflection height (Jacobson et al., 2010) to be $\sim 90 \mathrm{~km}$ for the known distance of $\sim 571 \mathrm{~km}$ between the lightning discharge and the radio receiver as inferred from full wave radio wave propagation simulations with Finite-Difference-TimeDomain (FDTD) modeling. Electromagnetic waves with two or more ionospheric reflections are more strongly attenuated and they are not detected above the background level of the interfering radio transmitters (Smith et al., 2004).

The burst of electromagnetic radiation from the electron beam at $\sim 4.4 \mathrm{~ms}$ is also composed of two consecutive pulses which are delayed by $\sim 59 \mu$ s (Fig. 5 , lower panel). The first pulse results from the direct wave which propagates at an angle to the receiver and is denoted direct wave. The second pulse results from the electromagnetic wave which is reflected from the ionosphere and is denoted sky wave. The time delay between the direct wave and the sky wave determines the height of the electron beam to be $\sim 41 \mathrm{~km}$ for the known ionospheric height of $\sim 90 \mathrm{~km}$ (Fig. 6). The electron beam is therefore located well above the thundercloud which terminates at an altitude of $\sim 12 \mathrm{~km}$. The burst of electromagnetic radiation at $\sim 8.9 \mathrm{~ms}$ emanates from a height of $\sim 72 \mathrm{~km}$ and could result from an independent second electron beam or from the same electron beam. In the the latter case, the second radiation burst is produced by an acceleration of the electrons within the beam, i.e., a displacement current. The electron beam would then propagate with an average velocity of $\sim 7000 \mathrm{~km} \mathrm{~s}^{-1}(\sim 0.023 \mathrm{c})$ through the middle atmosphere as inferred from the difference between the two emission heights of $\sim 31 \mathrm{~km}$ and the corresponding time delay $\sim 4 \mathrm{~ms}$. The heights of two more electron beams associated with other sprite discharges during the same night are determined to be $\sim 16 \mathrm{~km}$ and $\sim 22 \mathrm{~km}$, both of which are well above the thundercloud.

\section{Discussion}

A sensitivity analysis of the height determination methodology reveals that a variation of the observed time delay by $\sim 1 \mu$ s corresponds to a $\sim 1 \mathrm{~km}$ vertical height variation such that the height of the electron beam can be determined in a very accurate way. If the observed time delay is interpreted as a variation in the distance between the source and the receiver, $\sim 1 \mu$ s would correspond to a $\sim 10 \mathrm{~km}$ distance difference, such that the source would be well outside the area of the mesoscale convective system. Another sensitivity analysis was performed to determine the optimum distance between the lightning discharge and the radio receiver which maximizes the signals of the ground and sky 
wave. This distance was found to be $\sim 300-400 \mathrm{~km}$ such that at larger distances, it becomes increasingly difficult to distinguish the ground and sky wave from the background noise of the interfering radio transmitters. Finally, all lightning discharges with a peak current $\left|I_{p}\right|>30 \mathrm{kA}$ reported by Météorage from 00:00-04:00 UTC on 31 August 2008, have been investigated. Only one additional electromagnetic radiation burst with a flat spectrum from $\sim 40-400 \mathrm{kHz}$ could be found which is similar to the three examples reported here. The burst follows $\sim 5 \mathrm{~ms}$ after two consecutive positive lightning discharges at 01:29:09.785 and 786 UTC (Table 1). This singular observation is indicative of a nonluminous relativistic electron beam without any sprite occurrence as evidenced by the two video cameras. The preliminary result suggests that lightning discharges may also cause relativistic electron beams above thunderclouds without producing sprites because the relativistic breakdown threshold is only $\sim 1 / 10$ of the conventional breakdown threshold. It is also possible that the observed electromagnetic radiation bursts are related to secondary sprite processes sometimes observed above thundercloud tops (Pasko, 2010; Marshall and Inan, 2007; Moudry, 2003). However, these processes remained sub-visual in the optical observations reported in this work, and it is not clear why such a hypothetical process would emit low frequency electromagnetic radiation while the sprite itself does not. It is interesting to note that the low frequency electromagnetic radiation reported here can be observed in space as a result of its transionospheric propagation (Füllekrug et al., 2011, 2009) and it may be associated with high frequency electromagnetic radiation (Parrot et al., 2008).

\section{Summary}

In summary, relativistic electron beams above thunderclouds have been detected in association with sprites. The electron beams can coincide with sprites but they are then located above the thundercloud and below the main body of sprites. The electron beams can also occur shortly after the sprite luminosity. Both results suggest that non-luminous electron beams and luminous sprites independently discharge lightning electric fields in the middle atmosphere. The observed relativistic electron beams above thunderclouds occur simultaneously with $\sim 5 \%$ of all optically observed sprites and they are thus very rare. The small number of photons possibly emanating from non-luminous relativistic electron beams and sub-visual streamers may be identified in future studies by combining more sensitive optical observations with interferometric radio recordings to map the low-frequency radio sky above thunderclouds. However, the relativistic electron beams are a new form of impulsive energy transfer between thunderclouds and the middle atmosphere which need to be considered as a novel element in the global atmospheric electric circuit (Rycroft and Odzimek, 2010; Rycroft, 2006; Rycroft et al., 2000).

\section{Methods}

The Meteosat Second Generation satellite measures the thermal infrared radiation of the Earth from 10.5-12.5 $\mu \mathrm{m}$ with a Ritchey-Chrétien telescope connected to a $\mathrm{HgCdTe}$ detector. This passive imaging radiometer is calibrated with two black bodies at $290 \mathrm{~K}$ and $340 \mathrm{~K}$ and it scans the full Earth disk every $15 \mathrm{~min}$. The optical camera system on Pic du Midi consists of a wide-angle, low-light, video camera and a high-speed photometer mounted on a pan-tilt unit. The camera is equipped with a $16 \mathrm{~mm}, \mathrm{f} 1.40$ lens with a field of view of $31^{\circ}$ and it has an exposure time of $40 \mathrm{~ms}$ for one image. The photometer counts photon emissions at a sampling rate of $20 \mathrm{kHz}$ with a time resolution of $50 \mu \mathrm{s}$. The camera system is synchronized to UTC with a Global Positioning Satellite (GPS) receiver with an absolute timing accuracy $<1 \mathrm{~ms}$. The optical camera system in Sant Vicenç de Castellet is a Watec $902 \mathrm{H} 2$ equipped with a $12 \mathrm{~mm}$, f 0.8 lens with a field of view of $31^{\circ}$ and an exposure time of $20 \mathrm{~ms}$. The French lightning detection system Météorage covers southwestern Europe and the western Mediterranean Sea. The radio detection system of 18 sensors reports cloudto-ground lightning discharges with a detection efficiency of $\sim 90 \%$, peak current accuracy of $\sim 5 \%$, location accuracy $<4 \mathrm{~km}$, and timing accuracy $<1 \mathrm{~ms}$. The wideband digital radio receiver near Bath in the UK measures the vertical electric field strength by use of a capacitive probe with a sampling frequency of $1 \mathrm{MHz}$, frequency response from $\sim 4 \mathrm{~Hz}$ to $\sim 400 \mathrm{kHz}$, amplitude resolution of $\sim 35 \mu \mathrm{V}$, and timing accuracy of $\sim 12 \mathrm{~ns}$. Numerical simulations of relativistic electron beams are performed with the transient, multimaterial, compressible, fluid dynamics code CAVEAT which was adapted to solve the electromagnetic equations and their effect on the electron and ion populations in a selfconsistent way on the Los Alamos National Laboratory supercomputer facility. The Finite-Difference-Time-Domain (FDTD) method dynamically solves Maxwell's equations on a spatial grid using equivalent vertical current sources representing the relativistic electron beam and the causative lightning discharge and propagates the full wave radio electromagnetic fields to the wideband digital radio receiver.

Acknowledgements. This work was sponsored by the Natural Environment Research Council (NERC) under grant NE/H024921/1 and the Science and Technology Facilities Council (STFC) under grant PP/E0011483/1. V.P.P. was supported by Aeronomy and Physical and Dynamical Meteorology Programs of the US National Science Foundation. The International Space Science Institute (ISSI) kindly supported and hosted the Coupling of Atmospheric Regions with Near-Earth Space (CARNES) team meetings which stimulated this work.

Edited by: A. J. G. Baumgaertner 


\section{References}

Briggs, M., Connaughton, V., Wilson-Hodge, C., Preece, R., Fishman, G., Kippen, R., Bhat, P., Paciesas, W., Chaplin, V., Meegan, C., von Kienlin, A., Greiner, J., Dwyer, J., and Smith, D.: Electron-positron beams from terrestrial lightning observed with Fermi GBM, Geophys. Res. Lett., 38, 1-5, doi:10.1029/2010GL046259, 2011.

Carlson, B., Lehtinen, N., and Inan, U.: Observations of terrestrial gamma-ray flash electrons, in: Coupling of thunderstorms and lightning discharges to near-Earth space, edited by Crosby, N., Huang, T., and Rycroft, M., 84-91, American Institute of Physics, Melville, 2009.

Celestin, S. and Pasko, V.: Energy and fluxes of thermal runaway electrons produced by exponential growth of streamers during the stepping of lightning leaders and in transient luminous events, J. Geophys. Res., 116, 1-14, doi:10.1029/2010JA016260, 2011.

Cohen, M., Inan, U., Said, R., Briggs, M., Fishman, G., Connaughton, V., and Cummer, S.: A lightning discharge producing a beam of relativistic electrons into space, Geophys. Res. Lett., 37, 1-4, doi:10.1029/2010GL044481, 2010.

Colman, J., Roussel-Dupré, R., and Triplett, L.: Temporally selfsimilar electron distribution functions in atmospheric breakdown: The thermal runaway regime, J. Geophys. Res., 115, 117, doi:10.1029/2009JA014509, 2010.

Cummer, S., Li, J., Han, F., Lu, G., Jaugey, N., Lyons, W., and Nelson, T.: Quantification of the troposphere-to-ionosphere charge transfer in a gigantic jet, Nat. Geosci., 2, 617-620, doi:10.1038/NGEO607, 2009.

Daniel, R. and Stephens, S.: Cosmic-ray-produced electrons and gamma rays in the atmosphere, Rev. Geophys. Space Ge., 12, 233-258, 1974.

Dwyer, J., Grefenstette, B., and Smith, D.: High-energy electron beams launched into space by thunderstorms, Geophys. Res. Lett., 35, 1-5, doi:10.1029/2007GL032430, 2008.

Dwyer, J., Uman, M., and Rassoul, H.: Remote measurements of thundercloud electrostatic fields, J. Geophys. Res., 114, 1-19, doi:10.1029/2008JD011386, 2009.

Fishman, G., Bhat, P., Mallozzi, R., Horack, J., Koshut, T., Kouveliotou, C., Pendleton, G., Meegan, C., Wilson, R., Paciesas, W., Goodman, S., and Christian, H.: Discovery of intense gammaray flashes of atmospheric origin, Science, 264, 1313-1316, 1994.

Franz, R., Nemzek, R., and Winckler, J.: Television image of a large upward electrical discharge above a thunderstorm system, Science, 249, 48-51, 1990.

Füllekrug, M.: Wideband digital low-frequency radio receiver, Meas. Sci. Technol., 21, 1-9, doi:10.1088/09570233/21/1/015901, 2010.

Füllekrug, M., Mareev, E., and Rycroft, M. (eds.): Sprites, elves and intense lightning discharges, Springer, Dordrecht, The Netherlands, 2006.

Füllekrug, M., Parrot, M., Ash, M., Astin, I., Williams, P., and Talhi, R.: Transionospheric attenuation of $100 \mathrm{kHz}$ radio waves inferred from satellite and ground based observations, Geophys. Res. Lett., 36, 1-4, doi:10.1029/2008GL036988 2009.

Füllekrug, M., Roussel-Dupré, R., Symbalisty, M. D., Chanrion, O., Odzimek, A., van der Velde, O., and Neubert, T.: Relativistic runaway breakdown in low frequency radio, J. Geophys. Res., 115, 1-10, doi:10.1029/2009JA014468, 2010.
Füllekrug, M., Hanuise, C., and Parrot, M.: Experimental simulation of satellite observations of $100 \mathrm{kHz}$ radio waves from relativistic electron beams above thunderclouds, Atmos. Chem. Phys., 11, 667-673, doi:10.5194/acp-11-667-2011, 2011.

Gurevich, A. and Zybin, K.: Runaway breakdown and the mysteries of lightning, Phys. Today, 58, 37-43, 2005.

Gurevich, A., Milikh, G., and Roussel-Dupré, R.: Runaway electron mechanism of air breakdown and preconditioning during a thunderstorm, Phys. Lett. A, 165, 463-468, 1992.

Gurevich, A., Duncan, L., Karashtin, A., and Zybin, K.: Radio emission of lightning initiation, Phys. Lett. A, 312, 228-237, doi:10.1016/S0375-9601(03)00511-5, 2003.

Gurevich, A., Mitko, G., Antonova, V., Chubenko, A., Karashtin, A., Kryukov, S., Naumov, A., Pavljuchenko, L., Ptitsyn, M., Ryabov, V., Shalamova, S., Shepetov, A., Shlyugaev, Y., Vildanova, L., and Zybin, K.: An intracloud discharge caused by extensive atmospheric shower, Phys. Lett. A, 373, 3550-3553, doi:10.1016/j.physleta.2009.07.085, 2009.

Inan, U.: Gamma rays made on Earth, Science, 307, 1054-1055, 2005.

Jacobson, A., Shao, X., and Holzworth, R.: Full-wave reflection of lightning long-wave radio pulses from the ionospheric D region: Comparison with midday observations of broadband lightning signals, J. Geophys. Res., 115, 1-12, doi:10.1029/2009JA014540, 2010.

Krehbiel, P., Riousset, J., Pasko, V., Thomas, R., Rison, W., Stanley, M., and Edens, H.: Upward electrical discharges from thunderstorms, Nat. Geosci., 1, 233-237, doi:10.1038/ngeo162, 2008.

Luque, A. and Ebert, U.: Emergence of sprite streamers from screening-ionization waves in the lower ionosphere, Nat. Geosci., 2, 757-760, doi:10.1038/NGEO662, 2009.

Marshall, R. and Inan, U.: Possible direct cloud-to-ionosphere current evidenced by sprite-initiated secondary TLEs, Geophys. Res. Lett., 34, 1-4, doi:10.1029/2006GL028511, 2007.

Marshall, T., McCarthy, M., and Rust, W.: Electric field magnitudes and lightning initiation in thunderstorms, J. Geophys. Res., 100, 7097-7103, 1995.

Moss, G., Pasko, V., Liu, N., and Veronis, G.: Monte Carlo model for analysis of thermal runaway electrons in streamer tips in transient luminous events and streamer zones of lightning leaders, J. Geophys. Res., 111, 1-37, doi:10.1029/2005JA011350, 2006.

Moudry, D.: The dynamics and morphology of sprites, Fairbanks, Alaska, PhD thesis at University of Alaska Fairbanks, 2003.

Neubert, T., Rycroft, M., Farges, T., Blanc, E., Chanrion, O., Arnone, E., Odzimek, A., Arnold, N., Enell, C., Turunen, E., Bösinger, T., Mika, A., Haldoupis, C., Steiner, R., Van der Velde, O., Soula, S., Berg, P., Boberg, F., Thejll, P., Christiansen, B., Ignaccolo, M., Füllekrug, M., Verronen, P., Montanya, J., and Crosby, N.: Recent results from studies of electric discharges in the mesosphere, Surv. Geophys., 29, 71-137, doi:10.1007/s10712-008-9043-1, 2008.

Østgaard, N., Gjesteland, T., Stadsnes, J., Connell, P., and Carlson, B.: Production altitude and time delays of the terrestrial gamma flashes: Revisiting the Burst and Transient Source Experiment spectra, J. Geophys. Res., 113, 1-14, doi:10.1029/2007JA012618, 2008.

Parrot, M., Inan, U., Lehtinen, N., Blanc, E., and Pincon, J.: HF signatures of powerful lightning recorded on DEMETER, J. Geophys. Res., 113, 1-7, doi:10.1029/2008JA013323, 2008. 
Pasko, V.: Recent advances in theory of transient luminous events, J. Geophys. Res., 115, 1-24, doi:10.1029/2009JA014860, 2010.

Pasko, V. and George, J.: Three-dimensional modeling of blue jets and blue starters, J. Geophys. Res., 107, 1-16, doi:10.1029/2002JA009473, 2002.

Pasko, V., Inan, U., and Bell, T.: Spatial structure of sprites, Geophys. Res. Lett., 25, 2123-2126, 1998.

Pasko, V., Stanley, M., Mathews, J., Inan, U., and Wood, T.: Electrical discharge from a thundercloud top to the lower ionosphere, Nature, 416, 152-154, 2002.

Rakov, V. and Uman, M.: Lightning, physics and effects, Cambridge University Press, Cambridge, 2003.

Riousset, J., Pasko, V., and Bourdon, A.: Air-density-dependent model for analysis of air heating associated with streamers, leaders, and transient luminous events, J. Geophys. Res., 115, 1-22, doi:10.1029/2010JA015918, 2010.

Roussel-Dupré, R. and Gurevich, A.: On runaway breakdown and upward propagating discharges, J. Geophys. Res., 101, 22972311, 1996.

Roussel-Dupré, R., Symbalisty, E., Taranenko, Y., and Yukhimuk, V.: Simulations of high-altitude discharges initiated by runaway breakdown, J. Atmos. Sol-Terr. Phys., 60, 917-940, 1998.

Rycroft, M.: Electrical processes coupling the atmosphere and ionosphere: An overview, J. Atmos. Sol-Terr. Phys., 68, 445456, doi:10.1016/j.jastp.2005.04.009, 2006.

Rycroft, M. and Odzimek, A.: Effects of lightning and sprites on the ionospheric potential, and threshold effects on sprite initiation, obtained using an analog model of the global atmospheric electric circuit, J. Geophys. Res., 115, 1-18, doi:10.1029/2009JA014758, 2010.
Rycroft, M., Israelsson, S., and Price, C.: The global atmospheric electric circuit, solar activity and climate change, J. Atmos. Sol.Terr. Phys., 62, 1563-1576, 2000.

Said, R., Inan, U., and Cummins, K.: Long-range lightning geolocation using a VLF radio atmospheric waveform bank, J. Geophys. Res., 115, 1-19, doi:10.1029/2010JD13863, 2010.

Sentman, D., Wescott, E., Osborne, D., Hampton, D., and Heavner, M.: Preliminary results from the Sprites 94 aircraft campaign: 1. Red sprites, Geophys. Res. Lett., 22, 1205-1208, 1995.

Shao, X., Hamlin, T., and Smith, D.: A closer examination of terrestrial gamma-ray flash-related lightning processes, J. Geophys. Res., 115, 1-8, doi:10.1029/2009JA014835, 2010.

Smith, D., Heavner, M., Jacobson, A., Shao, X., Massey, R., Sheldon, R., and Wiens, K.: A method for determining intracloud lightning and ionospheric heights from VLF/LF electric field records, Radio Sci., 39, 1-11, doi:1029/2002RS002790, 2004.

Smith, D., Lopez, L., Lin, R., and Barrington-Leigh, C.: Terrestrial gamma-ray flashes observed up to $20 \mathrm{MeV}$, Science, 307, 10851088, doi:10.1126/science.1107466, 2005.

Soula, S., Van der Velde, O., Montanyà, J., Neubert, T., Chanrion, O., and Ganot, M.: Analysis of thunderstorm and lightning activity associated with sprites observed during the EuroSprite campaigns: Two case studies, Atmos. Res., 91, 514528, doi:10.1016/j.atmosres.2008.06.017, 2009.

Su, H., Su, R., Chen, A., Wang, Y., Hsiao, W., Lai, W., Lee, L., Sato, M., and Fukunishi, H.: Gigantic jets between a thundercloud and the ionosphere, Nature, 423, 974-976, doi:10.1038/nature01759, 2003. 